\title{
'Internal bracing' surgery in the management of solid tumor metastases of the thoracic and lumbar spine
}

\author{
ALBERTO DI MARTINO $^{1}$, BRUNO VINCENZI ${ }^{2}$, LUCA DENARO $^{3}$, SIMONA ANGELA BARNABA $^{1}$, \\ ROCCO PAPALIA $^{1}$, DANIELE SANTINI ${ }^{2}$, GIUSEPPE TONINI ${ }^{2}$ and VINCENZO DENARO ${ }^{1}$ \\ Departments of ${ }^{1}$ Orthopaedics and Trauma Surgery, ${ }^{2}$ Medical Oncology, University \\ Campus Bio-Medico, ${ }^{3}$ Neurosurgery, Catholic University School of Medicine, Rome, Italy
}

Received April 10,2008; Accepted September 2, 2008

DOI: 10.3892/or_00000241

\begin{abstract}
In patients with thoracolumbar spine metastasis, surgery is aimed at patient healing only when patient has a good prognosis with long life expectancy. In patients with short life expectancy a less aggressive surgical approach of posterior decompression and stabilization could improve patient care and allow for neurological recovery. Thirty-two consecutive patients affected by symptomatic thoracolumbar spine metastases with short life expectancy and good Karnofsky index (50-70) were subjected to surgery and reviewed retrospectively. After tumor embolization, surgery consisted of posterior decompression and stabilization with laminar hooks in the dorsal spine, and laminar hooks or lumbar pedicle screws. Patient's Karnofsky Index, average survival, Frankel neurological status, and pain were recorded before and after surgery, together with surgery related complications. Primary tumors were breast carcinoma (nine patients), renal cell carcinoma (three), lung carcinoma (four), GI tract carcinoma (six), prostate carcinoma (two), carcinoma of the uterus (two), melanoma (three), and malignant tumors at other different sites (three). Average survival after surgery was 23 months, with highest survival rates in renal cancer and breast carcinoma patients, and poorest survival rates in lung and dedifferentiated carcinoma. Karnofsky index improved from average 61 to $72 \%$ posto-peratively. After surgery patients experienced significant overall improvement of Frankel score and decrease of referred pain. Hospitalization stay was on average 10 days. Results showed that operative treatment of symptomatic spinal metastases in patients with poor prognosis and good general health status improves or preserves neurological function, allows for adjuvant treatments to be performed and has a role in improving general health status in most patients.
\end{abstract}

Correspondence to: Dr Alberto Di Martino, Department of Orthopaedics and Trauma Surgery, University Campus Bio-Medico, Via Alvaro Del Portillo 200, Rome 00155, Italy

E-mail: a.dimartino@unicampus.it

Key words: metastases, spine surgery, quality of life, neurological status

\section{Introduction}

Spine is the most common site of localization of tumor metastasis of the skeleton, $\sim 50 \%$ of bony metastasis affect the vertebrae (1). Reportedly the dorsal and lumbar tract are the most affected spinal segments $(2,3)$.

Neoplastic tissue tends to primarily affect the posterior half of the vertebral body, while the anterior portion of the vertebral body and the posterior structures are involved later, usually after direct extension of the tumor mass (4).

Clinically, spinal metastasis can be characterized by fixed local pain due to periosteal stretching, unrelated to loadings or, alternatively by pain due to a structural failure of the vertebrae and then related to loads $(5,6)$.

Spinal cord or radicular compressions occur in $\sim 10 \%$ of patients with spinal metastasis, following either a pathological fracture of the vertebral bodies, or the direct extension of the tumor mass arising from the vertebral body and compromising the spinal cord or the nerve roots by a local vascular impairment. The conflict between the container and the content, with subsequent cord compression, most commonly occurs in the thoracic segment, and is characterized by weakness, intense pain and later loss of stability, terminally compromising the sphincteric function $(7,8)$.

Radiotherapy is suggested as the first line treatment in case of sensitive tumors when segmental instability is not evident, when the neurological picture is stable, in case of reduced life span and in case of spinal cord compressions lasting $>24 \mathrm{~h}$ (5).

Surgery does not have only a palliative function, and has to be taken into consideration only in selected patients (9); principal aims of surgery are the treatment of pain, instability and cord or radicular compression, in order to allow for a global improvement of the clinical picture of the patient. Surgery is aimed at patient healing only when spinal metastasis is the only secondary localization and the primary tumor has a good prognosis with long life expectancy (most frequently in case of renal cancer or hormone sensitive tumors such as breast cancer and prostate cancer). In these cases, the metastasis is addressed as a primary vertebral tumor and treated with en bloc excision (10).

In patients with short life expectancy, similarly to what the authors described in the cervical spine (11), also in the thoracolumbar spine it is possible to perform a stabilization 


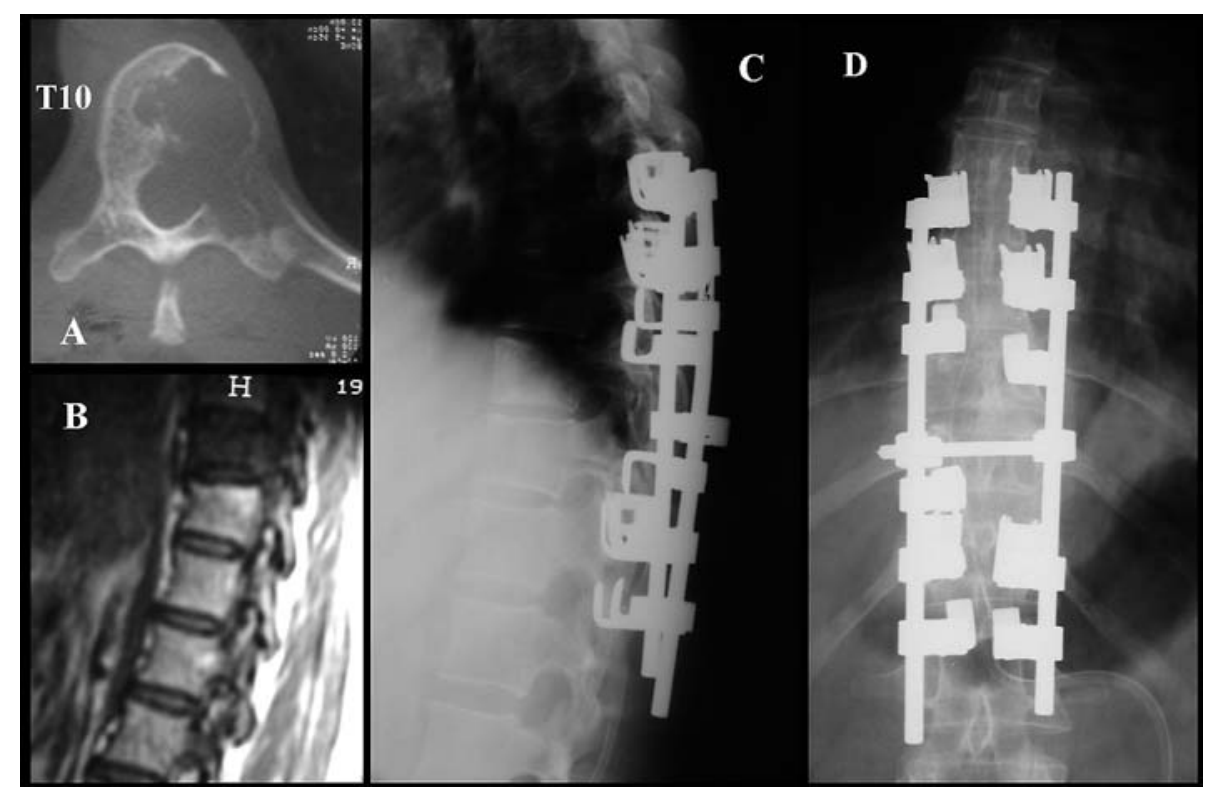

Figure 1. NB, female 63AA affected by breast cancer with an osteolythic metastatis at T10, as seen in the CT scan (A) and T1 gadolinium enhanced MRI (B). Patient was subjected to segmental decompression and stabilization with laminar and pedicle hooks and longitudinal bars (C and D).

with an 'internal bracing', represented by a posterior spinal construct of rods and laminar hooks and, in selected cases, screws. This less aggressive surgical approach can be indicated to improve patient care and quality of life. Clinical results with this treatment in selected patients affected by metastasis of the dorsal and lumbar spine with poor prognosis and good general status are reported.

\section{Materials and methods}

A retrospective analysis was performed on 32 patients affected by symptomatic spinal metastases with short life expectancy and good Karnofsky index (50-70) and who underwent surgery between January 1996 and January 2006 at the University Hospital of Campus Bio-Medico of Rome. At the time of review in June 2006, 3 patients were still alive. All the other patients died by that time of causes related to the primary neoplasm. None of the 32 patients had symptomatic brain metastases before surgery. In 6 of 32 patients (19\%), no other evidence of extraskeletal metastatic disease (e.g., lung or liver) was detected before surgery.

Patients affected by spinal metastases and operated via an anterior approach in that period were not considered for the study, indications for anterior intervention being a symptomatic lesion involving the anterior spine elements, with acceptable general health and good prognosis (12). Surgery consisted of posterior decompression and stabilization with laminar or pedicle hooks in the dorsal spine (Fig. 1), and hooks or pedicle screws representing the bottom part of the posterior instrumentation in the lumbar spine (Fig. 2). When hooks only were used for stabilization, construct usually extended from three levels above and below the affected vertebra. Pedicle screws were used only in the lumbar spine or in the lower thoracic spine (T10 to T12), when vertebral bodies were not involved by the neoplastic process; in this case, it extended for two levels below the tumor vertebrae and two or three above.
To reduce intraoperative blood loss, spinal angiography with tumor embolization was performed in all patients within 24-48 h before surgery. Intraoperative homologous blood was not collected or transfused to avoid possible tumor cell contamination; allogeneic blood was transfused when needed.

Radiation and/or chemotherapy was performed after surgery in 23 patients treated by surgical procedures. In the remaining 9 surgical procedures, patients received no additional radiation therapy for different reasons (e.g., low RT response of the neoplasm, poor general health or complications) and were usually treated by chemotherapy alone.

Postoperative mobilization was initiated with an additional three point external brace or a customized plastic brace molded in extension, after 3 days when compatible with neurological status of the patient. To assess the patient's general health, the Karnofsky Index was used; for neurologic function, the Frankel score was used. Pain was categorized on a scale ranging from no pain to mild, moderate, or severe pain. These data were recorded preoperatively and three months after surgery.

Statistical analysis was carried out using Chi-square analysis. Statistical significance was determined as a $\mathrm{P}<0.05$.

\section{Results}

Nineteen women and thirteen men with a mean age of 64 years (range: 44-72 years) were studied. Patients characteristics are reported in Table I.

The primary tumors were breast carcinoma (nine patients), lung carcinoma (four), gastrointestinal (GI) tract carcinoma ( $\mathrm{six}$ ), renal cell carcinoma (three), prostate carcinoma (two), carcinoma of the uterus (two), melanoma (three), and malignant tumors at other different sites (three).

The majority of symptomatic tumors involved the thoracic spine (21 patients), followed by the lumbar spine (11 patients). 


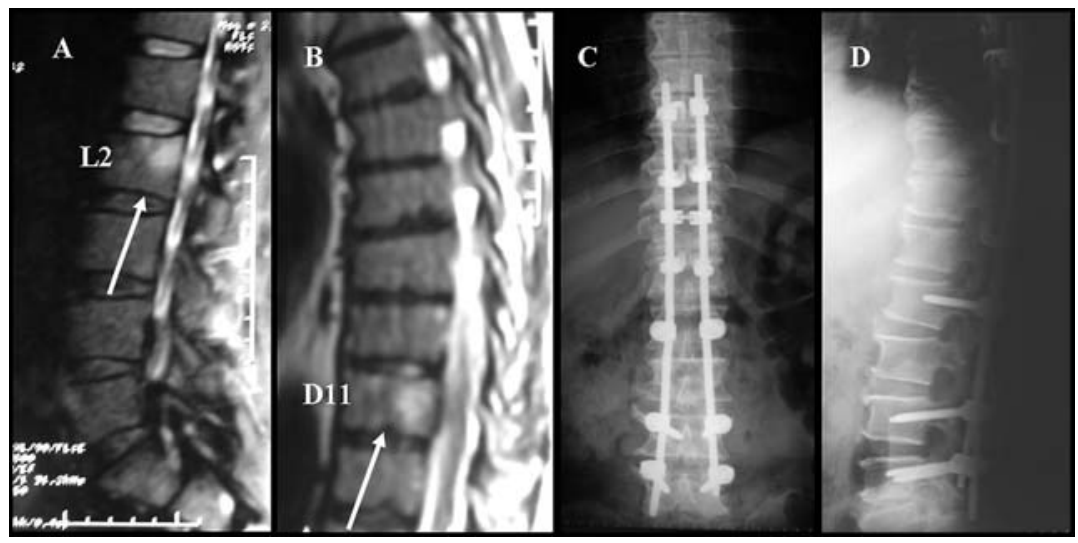

Figure 2. ASS, male 69 AA, affected by colon cancer with MRI confirmed metastasis (arrows) at L2 (A) and T11 (B). Surgery consisted in decompression and stabilization by a long hybrid construct with laminar hooks and longitudinal bars together with pedicle screws at the non-involved lumbar vertebral bodies (C and D).

Table I. Study population characteristics.

\begin{tabular}{lcccc}
\hline Primary tumor & $\begin{array}{c}\text { Total } \\
(\mathrm{n}=32)\end{array}$ & $\begin{array}{c}\text { Male } \\
(\mathrm{n}=13)\end{array}$ & $\begin{array}{c}\text { Female } \\
(\mathrm{n}=19)\end{array}$ & $\begin{array}{c}\text { Average survival } \\
23 \mathrm{mo}(6.2-60 \mathrm{mo})\end{array}$ \\
\hline Breast & 9 & $\mathrm{NA}$ & 9 & $38 \mathrm{mo}(1 \mathrm{still} \mathrm{alive})$ \\
Lung & 4 & 3 & 1 & $6.2 \mathrm{mo}$ \\
GI Tract & 6 & 3 & 3 & $48 \mathrm{mo}(1 \mathrm{still} \mathrm{alive})$ \\
Renal & 3 & 3 & - & $50 \mathrm{mo}(1 \mathrm{still} \mathrm{alive})$ \\
Prostate & 2 & 2 & $\mathrm{NA}$ & $28 \mathrm{mo}$ \\
Uterus & 2 & $\mathrm{NA}$ & 2 & $22 \mathrm{mo}$ \\
Melanoma & 3 & 1 & 2 & $16 \mathrm{mo}$ \\
Others & 3 & 1 & 2 & $9.3 \mathrm{mo}$ \\
\hline
\end{tabular}

NA, not applicable. mo, months.

Table II. Preoperative neurological grade according to Frankel and neurologic improvement after surgery.

\begin{tabular}{lcc}
\hline $\begin{array}{l}\text { Frankel } \\
\text { grade }\end{array}$ & $\begin{array}{c}\text { Preoperative } \\
\text { No. }\end{array}$ & $\begin{array}{c}\text { Postoperative } \\
\text { No. }\end{array}$ \\
\hline A & 0 & 0 \\
B & 9 & 4 \\
C & 12 & 8 \\
D & 7 & 11 \\
E & 4 & 9 \\
\hline
\end{tabular}

Mean postoperative survival time was 23 months (range: 6.2 months - 6 years). The highest survival rates were seen in patients with renal cell carcinoma (50 months) and breast carcinoma (38 months). The poorest survival rates were seen in patients with lung carcinoma (6.2 months) and dedifferentiated carcinoma (8.2 months).

The average postoperative status of the 32 patients was $72 \%$ on the Karnofsky Index, significantly improved compared
Table III. Perioperative complications.

\begin{tabular}{lc}
\hline & $\mathrm{n}=32$ \\
\hline Dural tears & 5 \\
Epidural vein bleeding & 6 \\
DVT & 4 \\
Wound infection & 3 \\
Myocardial infarction & 2 \\
\hline
\end{tabular}

to the preoperative average $61 \%(\mathrm{P}<0.05)$. In three patients, adjuvant therapy postoperatively was so effective that an anterior approach was performed.

Preoperative neurological grade according to Frankel and neurologic improvement after surgery are reported in Table II. Overall, 9 of $21(43 \%)$ nonambulatory patients (Frankel B/C) became ambulatory again (Frankel D). Only two patients experienced segmental sensory loss after surgery; these patients showed deterioration from Frankel Grade E to D. Overall, 62\% of patients were able to walk after surgery. 
Spinal pain (back pain and/or radicular pain) was present in all patients before surgery. In $65 \%$ of patients, back pain and/or radicular pain was severe, and in $25 \%$ it was moderate. After surgery patients experienced significant $(\mathrm{P}<0.05)$ decrease of referred pain: $81 \%$ reported much improved pain relief, and $13 \%$ reported moderate improvement; only $6 \%$ reported no change. No patient reported worsening of pain. Spinal pain relief was permanent, returning only in patients in whom local tumor recurrence or new metastatic spinal disease developed.

Perioperative complications are reported in Table III. There were no cases of intraoperative or early postoperative mortality. Hospitalization stay was on average 10 days (range: 8-13 days).

\section{Discussion}

Cancer patients with poor prognosis with symptomatic spinal metastasis pose a challenge as regards management and the need of a multidisciplinary approach. To date, there are multiple therapeutic options available for treatment, including systemic therapy, radiation, and surgery. The determination of the most appropriate timing for intervention can be difficult, but is quintessential; moreover, treatment should take into consideration patient prognosis and life span (12).

Surgical procedures applicable to patients affected by metastasis of the thoracolumbar spine can comprehend anterior and posterior decompressions and bone gap reconstructions, sometimes with a combination of both (13).

Surgery has to be taken into consideration only in selected patients (9), principal aims of surgery being the treatment of pain, instability and cord or radicular compression, in order to allow for a global improvement of the clinical picture of the patient; patient healing can be obtained only when spinal metastasis is the only secondary localization and a tumor with a good prognosis. In these cases, the metastasis is addressed as a primary vertebral tumor and treated with en bloc excision (10).

General health status is fundamental in respect to life span and complication rate when surgey is performed; Jansson and Bauer (14) reported on more than 280 patients treated over 10 years, that poor general status of the patients was directly related to a decrease in patient survival and an increase in complication rates.

For patients with short life expectancy affected by vertebral metastasis in the thoracic and/or lumbar spine, as described in the cervical spine (11), it is possible to perform a stabilization with an 'internal bracing', represented in this segment by a posterior spinal construct of rods and laminar hooks and, in selected cases, screws. This surgical approach allows for decompression of the neural structures and segmental stabilization; nonetheless, tumor bulk is only partially reduced when this approach is used, and radiotherapy and/or chemotherapy is necessary when ever possible $(15,16)$. Decompressive laminectomy and stabilization in these patients represents a rapid and less invasive therapeutic option. The 'internal bracing', represented by a posterior spinal construct of rods and laminar hooks, can often be performed in these patients, because the laminae of the vertebrae, differently from vertebral bodies and pedicles, are rarely involved by the neoplastic process, and the construct will therefore be stable (12).
This stabilization, associated to the segmental decompression after laminectomy, allowed improvement of the clinical and neurological picture of patients affected by multiple metastatic lesions of the thoracolumbar spine not eligible for complete excision of the tumor lesion (13); moreover, it allows for a late anterior approach after postsurgical adjuvant treatment. Our 3 patients subjected to internal bracing surgery underwent delayed anterior decompressive surgery after adjuvant treatment. When possible, anterior surgery should be performed, because improves the surgical result in patients affected by spinal metastasis (17-20); nonetheless, decompression and stabilization alone via a posterior approach allows in most cases to get a significant neurological recovery with reduced perioperative morbidity (21).

Shimizu et al (22) performed a study on patients affected by multiple spinal metastasis and neural compression and operated via a posterior approach alone. Surgery resulted in an improvement of the neurological picture in nine out of eleven cases $(81 \%)$, with better results in patients affected by breast cancer. Bauer (21), in a report on 67 patients affected by symptomatic spinal cord and root compression due to metastasis of the thoracolumbar spine and operated by a posterior approach, found a Frankel scale neurological improvement in $92 \%$ of patients with a pre-existing neurological symptom. As commonly observed in these patients complication rate was high, above all as regard postoperative infections (16\%).

Other authors (23-25) showed a role of surgery in patients with intractable back pain and neurological deficits, but in this particular subgroup of patients results on the neurological function were less impressive; poorer improvements were classically related to a decreased prognosis.

As observed by Chen et al (26) in 70 patients affected by TL spine metastasis, neurological recovery in these patients tend to be preserved over the life span.

In our cases, surgery has been effective in arresting the progression of neurological deterioration improving quality of life in the selected population.

On the basis of all these parameters, the results of this study clearly show that the operative treatment of symptomatic spinal metastases in patients with poor prognosis and good general health status improves or preserves neurological function, allows for adjuvant treatments to be performed and has a role in improving general health status of most patients.

\section{References}

1. Drew M and Dickinson RB: Osseus complication of malignancy. In: Clinical Cancer Medicine: Treatment Tactics. Lokich JJ (ed). MTP Press, Boston, MA, pp97-124, 1980.

2. Campanacci M: Metastatic bone disease. In: Bone and Soft Tissue Tumors. Campanacci M (ed). Springer-Verlag, New York, pp755-787, 1999.

3. Suen KC, Lau LL and Yermakov V: Cancer and old age: An autopsy study of 3535 patients over 65 years old. Cancer 33: 1164-1168, 1974

4. Adams M and Sonntang VKH: Surgical treatment of metastatic cervical spine disease. Contemp Neurosurg 23: 1-5, 2001.

5. Vrionis FD and Miguel R: Management of spinal metastases. Seminars in Pain Medicine 11: 25-33, 2003. 
6. Dewald RL, Bridwell KH, Prodromas $\mathrm{C}$ and Rodts MF: Reconstructive spinal surgery as palliation for metastatic malignancies of the spine. Spine 10: 21-26, 1985.

7. Galasko CSB: Spinal instability secondary to metastatic cancer. J Bone Joint Surg 73B, 1991.

8. Brihaye J, Ectors P, Lemort M and Van Houtte P: The management of spinal epidural metastases. Adv Tech Stand Neurosurg 16: 121-176, 1988.

9. Asdourian PL: Metastatic disease of the spine. In: The Textbook of Spinal Surgery. Budwell KH and DeWald RL (eds). Lippincott-Raven, Philadelphia, p2007, 1997.

10. Boriani S, Biagini R, De Iure F, Bertoni F, Malaguti MC, Di Fiore $M$ and Zanoni A: En bloc resections of bone tumors of the thoracolumbar spine. A preliminary report on 29 patients. Spine 21: 1927-1931, 1996.

11. Denaro V, Gulino G, Papapietro N and Denaro L: Treatment of metastasis of the cervical spine. Chir Organi Mov 83: 127-137, 1998

12. Denaro V, Di Martino A, Ippolito M and Papalia R: Surgical team in the management of bone metastasis. Supp Pall Cancer Care (Suppl) 2: 17-23, 2006.

13. Roy-Camille R, Judet TH, Saillant G., Mamoudy P and Denaro V: Tumeurs du Rachis. Encicl Med-Chir Techniquee Chirurgicales. Orthopedie pp44-165, 1982 .

14. Jansson KA and Bauer HC: Survival, complications and outcome in 282 patients operated for neurological deficit due to thoracic or lumbar spinal metastases. Eur Spine J 15: 196-202, 2006.

15. Gilbert RW, Kim JH and Posner JB: Epidural spinal cord compression from metastatic tumor. Diagnosis and treatment. Ann Neurol 3: 40-51, 1978.

16. Young RF, Post EM and King GA: Treatment of spinal epidural metastases. Randomized prospective comparison of laminectomy and radiotherapy. J Neurosurg 53: 741-748, 1980.

17. McLain RF and Weinstein JN: Tumors of the spine. Semin Spine Surg 2: 157-180, 1990
18. Harrington KD: Anterior decompression and stabilization of the spine as a treatment for vertebral collapse and spinal cord compression from metastatic malignancy. Clin Orthop Relat Res 233: 177-197, 1988.

19. Siegal T, Tiqva P and Siegal T: Vertebral body resection for epidural compression by malignant tumors. Results of fortyseven consecutive operative procedures. J Bone Joint Surg Am 67: 375-382, 1985

20. Kostuik JP, Errico TJ, Gleason TF and Errico CC: Spinal stabilization of vertebral column tumors. Spine 13: 250-256, 1988.

21. Bauer H: Posterior decompression and stabilization for spinal metastases: Analysis of sixty-seven consecutive patients. J Bone Joint Surg Am 79A: 514-522, 1997.

22. Shimizu K, Shikata J, Iida H, Iwasaki R, Yoshikawa J and Yamamuro T: Posterior decompression and stabilization for multiple metastatic tumors of the spine. Spine 17: 1400-1404, 1992.

23. Cappelletto B, Del Fabro P and Meo A: Decompression and surgical stabilization in the palliative treatment of vertebral metastases. Chir Organi Mov 83: 167-176, 1998.

24. Casadei R, Greggi T, Miglietta A, Perozzi M, Barchetti M, and Parisini P: Posterior surgery for the treatment of thoracolumbar pathologic fractures in metastatic patients. Chir Organi Mov 83: 149-158, 1998

25. Rompe JD, Hopf CG and Eysel: Outcome after palliative posterior surgery for metastatic disease of the spine-evaluation of 106 consecutive patients after decompression and stabilisation with the Cotrel-Dubousset instrumentation. Arch Orthop Trauma Surg 119: 394-400, 1999.

26. Chen LH, Niu CC, Fu TS, Lai PL, Wong CB and Chen WJ: Posterior decompression and stabilization for metastatic spine diseases. Chang Gung Med J 27: 903-910, 2004. 